takes one beyond experiment can lead to error as well as truth. From this period when there were still genetical giants in the land, one sees also, and with sobering modesty, that "new" ideas are invariably anticipated, that respect and dislike are compatible, that personal animosity can be a great stimulus to research and that public recantation is only for the strong.

There is pleasure as well as profit in this early period, and the reader will be both amused and bemused by Carlson's evaluation of Bateson's "Materials for the Study of Variation" as neither a professional nor a financial success though it led to his election as a Fellow of the Royal Society in the year of its publication.

The nostalgic will enjoy reading of the time when scientists fought their battles in the proceedings and transactions of learned societies, wore white and won their wars by scientific work. For nowadays it seems that their time is spent in committee combat, success is measured in annual grants, buildings and administrative power, and acclaim is pin-striped.

The contemporary status of a science is better comprehended by those who have a knowledge of its germination and development, for while accepted theory continues to be taught the experiments which led to its formulation are frequently forgotten. And there cannot be a more serious impediment to understanding than unawareness of ignorance. Carlson's book does much to correct this situation in genetics and it is a creditable contribution in the most difficult of all fields, that of anticipating the past.

K. R. LEWIS

\section{REDUCING UNCERTAINTY}

\section{Progress in Experimental Personality Research}

Edited by Brendan A. Maher. Vol. 3. Pp. xii +319. (New York: Academic Press, Inc.; London: Academic Press, Inc. (London), Ltd., 1966.) $76 s$.

THIs contribution falls conceptually into two parts: first, four reviews of mainly very recent experimental work on some specific motivational aspects of personality; and second, a substantial reconsideration of the explanatory power of twin studies for theories of schizophrenia. This cogently argued reappraisal by Gottesman and Shields is soberly critical of studies on which the genetic explanation of schizophrenia has rested for a long time. The critique is based on the following main points: biased and inadequate sampling; the heterogeneous basis of schizophrenia; the differences in concordance rates between males and females including the differences between samesex and opposite-sex fraternal twins' concordances; variability of concordance rates depending on country and date of study; degrees of chronicity; and symptom severity and similarity of disorder in the co-twins. The authors correctly conclude that genetic factors ". . . are necessary but not sufficient for the disorder to occur".

Austin Jones contributes a comprehensive account of new experiments in the area of "sensory deprivation", perhaps now to be rephrased "stimulus or information deprivation". He demonstrates fairly conclusively that information deprivation leads to information "hunger" which is proportional to the length of the deprivation period and information content of available stimulation. The results seem as relevant to astronaut efficiency as to developmental theories of schizophrenia.

J. O. Sines writes clearly though repetitively on the advantages of actuarial over clinical prediction in personality assessment and objective psychological diagnosis; an issue which must eventually effect changes in presentday psychiatric methodology.

Chapters by W. Mischel on experimental demonstrations of the role of imitation in the development of self-imposed delay of rewards, that is advantageous self-control in children, and by I. D. Steiner on the dynamic processes, with their homeostatic implication, underlying a good deal of human social conformity, complete a volume that is bound to be of arresting interest to many readers, and which further demonstrates that experimental psychology is "not so much a 'subject' but more a way of life" in the reduction of scientific uncertainty. VERNON HAMILTON

\section{OBITUARIES}

\section{Professor Hou Pao Chang}

Professor Hou Pao Chang died in Peking on March 12, 1967 , at the age of 74 after a short illness.

Hou was born in Fengtai in the Province of Anhwei, China, in 1894. He graduated M.D. in 1920 from the Peking Union Medical College and his career in pathology began on the staff of the Cheeloo University School of Medicine in 1923. In 1926 he won a Rockefeller Foundation Fellowship to study pathology, first in the University of Chicago and later in the University of Berlin, where he was trained by Ludwig Pick. He was always a disciple of Pick; this is witnessed by the copious records of pathological examinations which he compiled with meticulous accuracy to form the basis of his research. During a further period of study in Britain he made the acquaintance of pathologists from many British universities. He returned to Cheeloo as head of the department of pathology in 1936, and held this post until the SinoJapanese conflict. When Cheeloo University moved from Tsinan in the coastal province to Chengtu in the heart of west China and combined with the West China Union University, Hou was appointed head of the combined department of pathology of the two universities in 1938 and held this position until 1946. In the difficult wartime conditions he led a team of researchers into the mountainous regions of the far west to study indigenous diseases.

In 1948, after a brief stay in Britain and the United States, he accepted the appointment of professor of pathology in the University of Hong Kong and with it the challenge to reconstitute the department virtually from nothing. When he retired in $\mathbf{1 9 6 0}$ he left a modern department of pathology, involving all aspects of pathological science, housed in a spacious building. When he retired the title of emeritus professor and the degree D.Sc. honoris causa were conferred on him by the University of Hong Kong. But this was not the end of his career, for he then returned to Peking to continue at the Chinese Medical University his life's work of teaching pathology. His appointments as vice-president of the Chinese Medical University and as a member of the People's Political Consultative Council show the esteem in which he was held.

Hou was not only a pioneer of modern methods in China but also an authority with an international reputation in pathology. His learned interests were broad and profound, his publications were numerous and his participation in symposia and international meetings was frequent and distinguished. A topic which held his sustained interest over a number of years was the history of medicine in China; it was the subject of several papers and also of a book, which he was preparing at the time of his death.

Hou is remembered by his students, colleagues and friends in China and abroad. A colleague from England who visited him in Peking expressed the thoughts of many when he wrote, "I have been exceptionally fortunate in my friends; among them, one of the most important was Professor Hou, for whom I had the greatest admiration and affection as man, Chinese, scientist and friend".
C. T. HUANG 